\title{
VOLTAGE CLAMP ANALYSIS OF SODIUM CHANNELS IN NORMAL AND SCORPION TOXIN-RESISTANT NEUROBLASTOMA CELLS ${ }^{1}$
}

\author{
TOHRU GONOI,* BERTIL HILLE, $\$$ AND WILLIAM A. CATTERALL*,2 \\ ${ }^{*}$ Department of Pharmacology and $\ddagger$ Department of Physiology and Biophysics, University of Washington, \\ Seattle, Washington 98195
}

Received April 27, 1984; Accepted June 14, 1984

\begin{abstract}
Sodium currents mediated by voltage-sensitive sodium channels in normal and scorpion toxin-resistant neuroblastoma cells were measured using a giga-ohm seal recording method in the whole cell patch configuration. The voltage and time dependence of sodium currents were similar in normal and mutant cell lines. Halfmaximal activation occurred for test depolarizations in the range of -7 to $-11 \mathrm{mV}$. Half-maximal inactivation occurred for pre-pulses in the range of -62 to $-69 \mathrm{mV}$. Scorpion toxin from Leiurus quinquestriatus (100 to $200 \mathrm{nM}$ ) increased the time constant for sodium channel inactivation 6- to 9-fold, increased the peak sodium current $2.0 \pm 0.5$ fold, shifted the voltage dependence of sodium channel activation 7 to $11 \mathrm{mV}$ to more negative potentials, and made the voltage dependence of inactivation less steep. These effects were observed for both normal and scorpion toxin-resistant neuroblastoma cells. However, the effect of Leiurus toxin on the rate of inactivation was half-maximal at $1.7 \mathrm{nM}$ for the parental cell line $\mathrm{N} 18$, in contrast to 5.4 or $39 \mathrm{nM}$ for the scorpion toxin-resistant clone LV30 and 24 or $51 \mathrm{nM}$ for LV10. These results show that scorpion toxin resistance results from a specific change in channel properties that does not impair normal function but causes an increase in the apparent $K_{\mathrm{D}}$ for Leiurus toxin action on sodium channels.
\end{abstract}

The voltage-sensitive sodium channel is the membrane glycoprotein responsible for the sodium permeability changes of electrically excitable cells. Upon depolarization of the cell membrane under voltage clamp control, sodium channels first activate, causing an increase in sodium permeability, and then inactivate, entering a nonconducting, refractory state (Hodgkin and Huxley, 1952). One approach to understanding activation and inactivation at the molecular level is to identify the binding sites for agents that change them.

Two groups of neurotoxins bind specifically to distinct sites on voltage-sensitive sodium channels and modulate their gating properties. Lipid-soluble toxins such as batrachotoxin and veratridine bind to one receptor site and cause persistent activation of the channel. Polypeptide toxins from the venom of North African scorpions including Leiurus quinquestriatus and from sea anemone nematocysts bind to another site on the channel in a voltage-dependent manner. They slow inactivation gating and act cooperatively with the lipid-soluble toxins to cause persistent activation of the channel. These toxins have been used in biochemical experiments to identify the protein components of sodium channels (reviewed in Barchi, 1983; Catterall, 1984).

Genetic approaches provide a complementary method to

\footnotetext{
${ }^{1}$ This work was supported by National Science Foundation Research Grant BNS 80-21619 to W. A. C., National Institutes of Health Research Grant NS 08174 to B. H., and a Department of Defense University Research Instrumentation grant to B. H. and W. A. C.

${ }^{2}$ To whom correspondence should be addressed.
}

study the gating function of sodium channels. Neurotoxins that cause persistent activation of sodium channels are cytotoxic to electrically excitable neuroblastoma cells and have been used to select for mutant cells (West and Catterall, 1979). Neuroblastoma clones selected for resistance to the cytotoxic effects of veratridine plus Leiurus scorpion toxin have reduced numbers of functional sodium channels or channels with reduced affinity for Leiurus toxin as assessed from measurements of ${ }^{22} \mathrm{Na}^{+}$influx and neurotoxin binding (West and Catterall, 1979; Costa and Catterall, 1982). Such cell lines provide potential sources of structurally variant sodium channels for further analysis.

Sodium channels in cultured neuroblastoma cells have physiological characteristics similar to those in nerve axons as detemined by measurements of sodium currents using either a two-microelectrode voltage clamp (Moolenaar and Spector, 1978) or a low resistance whole cell suction clamp technique (Kostyuk et al., 1978; Huang et al., 1982). More recently, single sodium channel currents in neuroblastoma cells have been studied (Quandt and Narahashi, 1982; Aldrich et al., 1983) with the giga-ohm seal patch clamp technique (Hamill et al., 1981). We have used a modification of this method in the whole cell voltage clamp configuration to measure and compare macroscopic sodium currents of normal and scorpion toxin-resistant neuroblastoma cells.

\section{Materials and Methods}

Materials, Leiurus scorpion toxin was purified (Catterall, 1976) from venom purchased from Sigma Chemical Co. Other materials were obtained from the following sources: tetrodotoxin, Calbiochem; new- 
born calf serum, KC Biologicals; Dulbecco-Vogt modified Eagle's minimum essential medium (DMEM), Grand Island Biological Co.

Cell culture. N18 cells and related mutant cell lines (LV10 and LV30) were cultured in 100-mm-diameter Petri dishes for 5 to 8 days until cells became confluent. Details of the culture techniques were described previously (Catterall, 1975). Culture medium consisted of $5 \%$ newborn calf serum, 95\% DMEM. Three to $8 \mathrm{hr}$ before recordings, cells were harvested by trituration in $\mathrm{Ca}^{2+}$ - and $\mathrm{Mg}^{2+}$-free Dulbecco's phosphatebuffered saline and reseeded in 35-mm-diameter plastic dishes (Falcon 3001 ) containing $1 \mathrm{ml}$ of the culture medium at a cell density of $5 \times$ $10^{5}$ cells $/ \mathrm{ml}$. Reseeding enabled us to record from isolated spherical cells as required for voltage clamp measurements.

Voltage clamp recording. For recordings, the culture medium was replaced with $1 \mathrm{ml}$ of mammalian Ringer's solution $(150 \mathrm{~mm} \mathrm{NaCl}, 5$ $\mathrm{mM} \mathrm{KCl}, 1.5 \mathrm{mM} \mathrm{CaCl}, 1.0 \mathrm{mM} \mathrm{MgCl} 2,5 \mathrm{mM}$ glucose, $5 \mathrm{mM} \mathrm{Na} \mathrm{Na}^{+}$ HEPES, $\mathrm{pH}$ 7.4), and the plastic dish was mounted on a stage of an inverted phase-contrast microscope. All recordings were performed at room temperature $\left(20 \pm 1^{\circ} \mathrm{C}\right)$. In scorpion toxin dose-response measurements, the reseeded cells were incubated in mammalian Ringer's containing the indicated concentrations of scorpion toxin at $37^{\circ} \mathrm{C}$ for $30 \mathrm{~min}$ before recordings.

The voltage clamp was based on the one-pipette, giga-ohm seal whole cell recording technique (Hamill et al., 1981). Glass microtubes for hematocrit (Curtin Matheson Scientific Inc., $1.5 \mathrm{~mm}$, outer diameter) were pulled in two steps, and tips of the pipettes were fire polished. The tip resistances were from 0.2 to 1 megohm in mammalian Ringer's. Gentle suction applied after the pipette was in contact with the cell surface sufficed to form a seal and rupture the patch of membrane in the orifice. After 10 to $15 \mathrm{~min}$ the total input resistance of pipette and cell rose to $10^{8}$ to $10^{10} \mathrm{ohms}$. Two different internal pipette media were used: (1) $150 \mathrm{~mm}$ cesium aspartate, $5 \mathrm{mM}$ EGTA, $10 \mathrm{~mm}$ sodium aspartate, $\mathrm{pH}$ 7.4; and (2) $160 \mathrm{mM}$ CsF. Either solution blocked $\mathrm{K}^{+}$ currents and left similar sodium currents, but cells studied with solution 2 were more stable and often lasted more than $3 \mathrm{hr}$. Observations with the two different internal solutions are combined under "Results." The voltage clamp circuit used no electrodes other than a single bath electrode and the patch pipette. It therefore included a circuit for compensation of up to 1 megohm series resistance in the currentpassing pathway. Leak currents were subtracted electronically. The membrane capacitances of the cells studied ranged from 30 to $190 \mathrm{pF}$, and the time constants of decay of capacitive currents were typically 50 to $150 \mu \mathrm{sec}$ before the series resistance compensation was applied. Currents and potentials were displayed on a storage oscilloscope and photographed.

The cell was maintained at a holding potential of $-75 \mathrm{mV}$. For measurement of peak sodium currents, $I_{\mathrm{Na}}$, the membrane was hyperpolarized in a prepulse to $-105 \mathrm{mV}$ for $90 \mathrm{msec}$ to remove inactivation of sodium channels and then was depolarized to test potentials from $-60 \mathrm{mV}$ to $+105 \mathrm{mV}$ for $10 \mathrm{msec}$. For measurement of the voltage dependence of sodium channel inactivation, the prepulse potential was varied from $-135 \mathrm{mV}$ to $-30 \mathrm{mV}$. The test pulse was always to +7.5 $\mathrm{mV}$.

Several parameters were evaluated to summarize the observations. The maximum inward $I_{\mathrm{Na}}$ was determined from peak $I_{\mathrm{Na}}$-voltage plots and usually occurred near $+7.5 \mathrm{mV}$. Peak currents were also converted to sodium conductance, $g_{\mathrm{Na}}$, by the relation

$$
g_{\mathrm{Na}}=\mathrm{I}_{\mathrm{Na}} /\left(E-E_{\mathrm{Na}}\right)
$$

where $E$ is membrane potential and $E_{\mathrm{Na}}$ is the reversal potential for current in sodium channels. Activation was characterized by the voltage required to reach half-maximal $g_{\mathrm{Na}}, E\left(g_{\mathrm{Na}}=0.5\right)$. Steady-state inactivation was described by the midpoint $E_{\mathrm{h}}$ and steepness $k_{\mathrm{h}}$ of the inactivation curve obtained with the following equation:

$$
h_{\infty}=1 /\left[1-\exp \frac{\left(E-E_{\mathrm{h}}\right)}{k_{\mathrm{h}}}\right]
$$

The decay of $I_{\mathrm{Na}}$ during a depolarizing test pulse was characterized by the exponential time constant of inactivation $\tau_{h}$. The membrane capacity was calculated from the area (charge) under the capacity current transient in a voltage step from -75 to $-67.5 \mathrm{mV}$. When referred to the apparent surface area of the cell taken as a sphere, the specific capacitance was $3.4 \pm 1.5 \mu \mathrm{F} / \mathrm{cm}^{2}$, indicating that the cells have 3 times more surface area than is apparent under an inverted phase contrast microscope. The conductances given in the Table I are referred to the visible surface rather than to that revealed by capacitance measurements.

\section{Results}

Sodium currents of normal and scorpion toxin-resistant neuroblastoma cells. Three cell lines were studied: the parental clone N18 and the scorpion toxin-resistant subclones LV10 (West and Catterall, 1979) and LV30 (Costa and Catterall, 1982). Typical families of currents for N18, LV10, and LV30 are illustrated in Figure 1 for depolarizing test pulses ranging from -60 to $+105 \mathrm{mV}$ in intervals of $15 \mathrm{mV}$. In each of these three cell lines, sodium channels activate within $1 \mathrm{msec}$ and inactivate before the end of the 10 -msec test pulse in a qualitatively similar manner.

To compare sodium currents of normal and scorpion toxinresistant cells quantitatively, cell cultures were prepared, grown, and analyzed under identical conditions. Characteristics of the amplitude and time course of the sodium permeability changes are summarized in Figure 2 and Table I. The sodium currents of many mutant cells were too small for reliable study and these cells are not included in Table I. The mutant cells with larger currents also achieved a lower mean maximum sodium conductance than N18 cells when normalized for cell surface area, but with the wide range of values recorded, the difference was not statistically significant. Previous flux experiments on whole dishes of cells (West and Catterall, 1979; Costa and Catterall, 1982) showed less ${ }^{22} \mathrm{Na}^{+}$influx in mutant cells and suggested that they have fewer functional channels.

The voltage dependence of sodium channel activation was
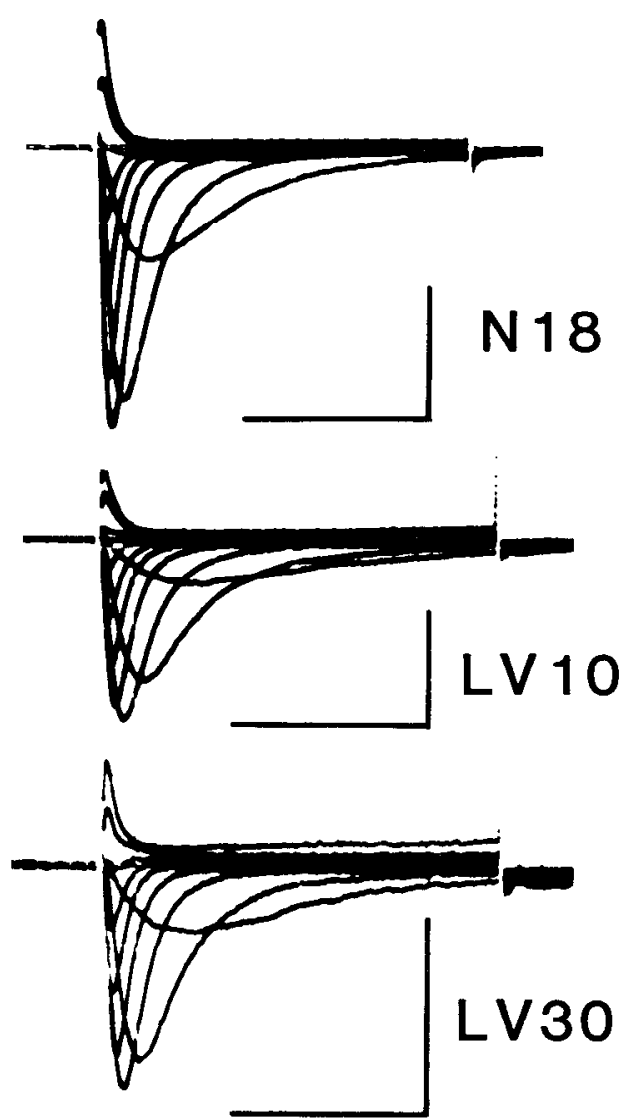

Figure 1. Sodium currents of N18, LV10, and LV30 cells under voltage clamp. Cell cultures were prepared and whole cell patch recordings were made as described under "Materials and Methods." Cells were maintained at a holding potential of $-75 \mathrm{mV}$, hyperpolarized to $-105 \mathrm{mV}$ for $90 \mathrm{msec}$, and depolarized once per second to potentials from $-60 \mathrm{mV}$ to $+105 \mathrm{mV}$ in $15-\mathrm{mV}$ intervals to elicit the sodium currents. The 12 traces are superimposed photographically by photographing the storage screen of the oscilloscope. Calibration: $5 \mathrm{msec}, 5$ nA. 
measured as in Figure 1 and the maximum conductance was calculated at each test membrane potential. These results (open symbols, Fig. 2) do not reveal any important difference in the voltage dependence of activation in the mutant cells. The halfmaximal activation lies between $-7 \mathrm{mV}$ and $-11 \mathrm{mV}$ for all three cell lines (Table I).

The voltage dependence of steady-state inactivation of sodium channels, $h_{\infty}$, was determined using a two-pulse procedure (Fig. 2). Stepping the prepulse progressively from membrane potentials of $-135 \mathrm{mV}$ to $-30 \mathrm{mV}$ inactivates an increasing fraction of the sodium channels and decreases the resulting sodium currents (solid symbols, Fig. 2). The voltage dependence of inactivation is similar for the three cell lines with halfmaximal inactivation at $-62 \mathrm{mV}$ to $-69 \mathrm{mV}$. (Fig. 2, Table I).

Parameters describing the time course of sodium currents, including the time to peak current and the time for half-decay of the currents, were similar for all three cell lines (Table I). These results show that sodium channels in scorpion toxinresistant neuroblastoma cells have essentially normal gating properties. Evidently, scorpion toxin resistance results from a specific change in channel properties that does not impair normal function.

Effects of Leiurus scorpion toxin on sodium currents in neuroblastoma cells. In previous work, toxins from North African

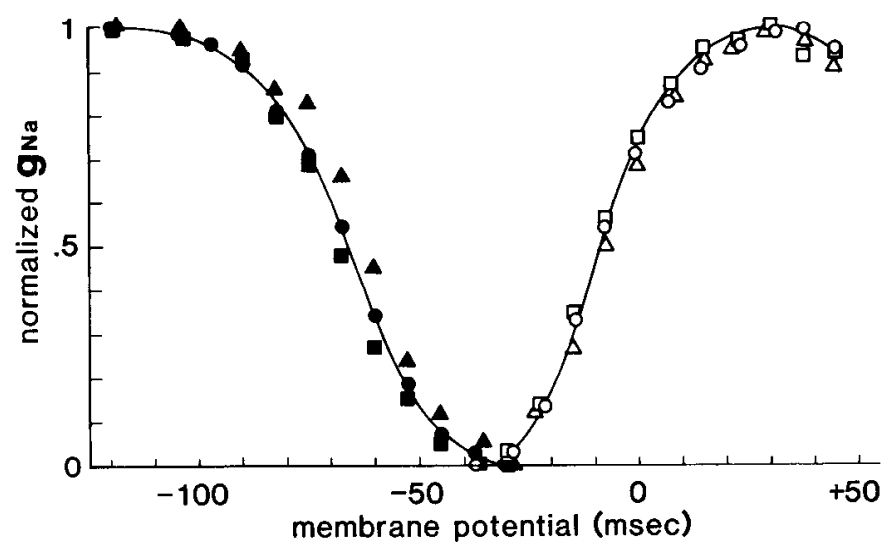

Figure 2. Voltage dependence of sodium channel activation and inactivation. The voltage dependence of sodium channel activation (open symbols) and inactivation (solid symbols) were measured as described under "Materials and Methods" for N18 (O, ๑), LV10 ( $\square$, $\boldsymbol{\square})$, and LV30 $(\triangle, \mathbf{A})$. Normalized values for inactivation were calculated as the ratio of $I_{\mathrm{Na}}$ following a prepulse at the indicated membrane potential to that following a prepulse to $-120 \mathrm{mV}$. Normalized values for activation were calculated as the ratio of $g_{\mathrm{Na}}$ during a test pulse at the indicated membrane potential to that during a test pulse to +30 $\mathrm{mV}$. scorpions like Leiurus̉ quinquestriatus have been shown to slow sodium channel inactivation without major effects on other aspects of the measured sodium currents (Koppenhöfer and Schmidt, 1968a, b; Romey et al., 1975; Okamoto et al., 1977; Catterall, 1979; Mozhayeva et al., 1980; Wang and Strichartz, 1983). In mouse neuroblastoma cells Leiurus toxin has two effects (Fig. 3). The decay of sodium currents is markedly slowed so that they no longer inactivate fully by the end of the test pulse (Fig. $3 C$ ). In addition, the toxin increases the maximum sodium current observed at all test potentials (Fig. $3 \mathrm{C}$ ). In $19 \mathrm{~N} 18$ cells studied, the mean increase at $0 \mathrm{mV}$ was $2.0 \pm$ 0.5 -fold (SE, 'I'able I). These two effects develop concurrently within $15 \mathrm{~min}$ after application of $200 \mathrm{nM}$ Leiurus toxin at $20^{\circ} \mathrm{C}$ (Fig. $3 B$ ). In the experiment of Figure 4 , the time course of decay of the sodium current during a test pulse to $+15 \mathrm{mV}$ is exponential with a time constant of $0.48 \mathrm{msec}$ before toxin treatment whereas, in the presence of $200 \mathrm{nM}$ Leiurus toxin, the time constant is increased to $4.9 \mathrm{msec}$. The slowed time course is still approximately exponential. At intermediate toxin concentrations, a biphasic decay consisting of a sum of components with normal and toxin-modified channel inactivation rates was observed. The two toxin-resistant clones, LV10 and LV30, respond in a similar way to saturating concentration (200 nM) of Leiurus toxin. As for N18 cells, the time constant for decay of the sodium current during a test pulse to $+15 \mathrm{mV}$ is increased 6- to 9 -fold and the peak sodium current is increased 1.9- to 2.0-fold (Table I). Thus, a saturating concentration of scorpion toxin has similar effects on sodium channels of normal and scorpion toxin-resistant cell lines.

Leiurus toxin changed the voltage dependence of activation

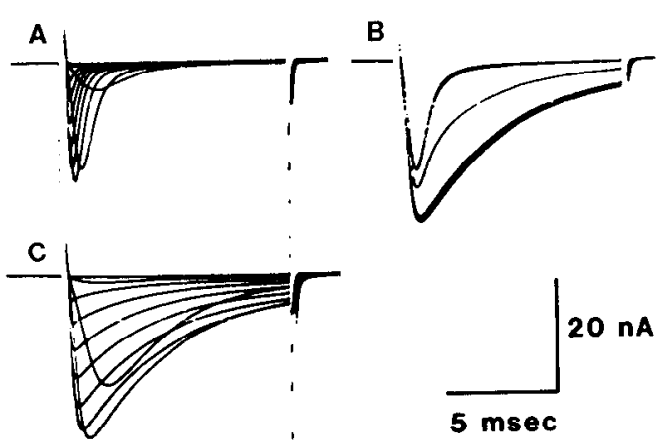

Figure 3. Effect of Leiurus toxin on sodium currents in N18 cells. $A$, Sodium currents were recorded $60 \mathrm{~min}$ after forming a seal with the electrode. $B$, Twenty microliters of $10 \mu \mathrm{M}$ Leiurus toxin were added to the bathing medium near the cell. Sodium currents were measured at 0,3 , and 8 min following addition of the toxin. $C$, A family of sodium currents was recorded $15 \mathrm{~min}$ after addition of Leiurus toxin.

TABLE I

Sodium current parameters in N18, LV10, and LV30

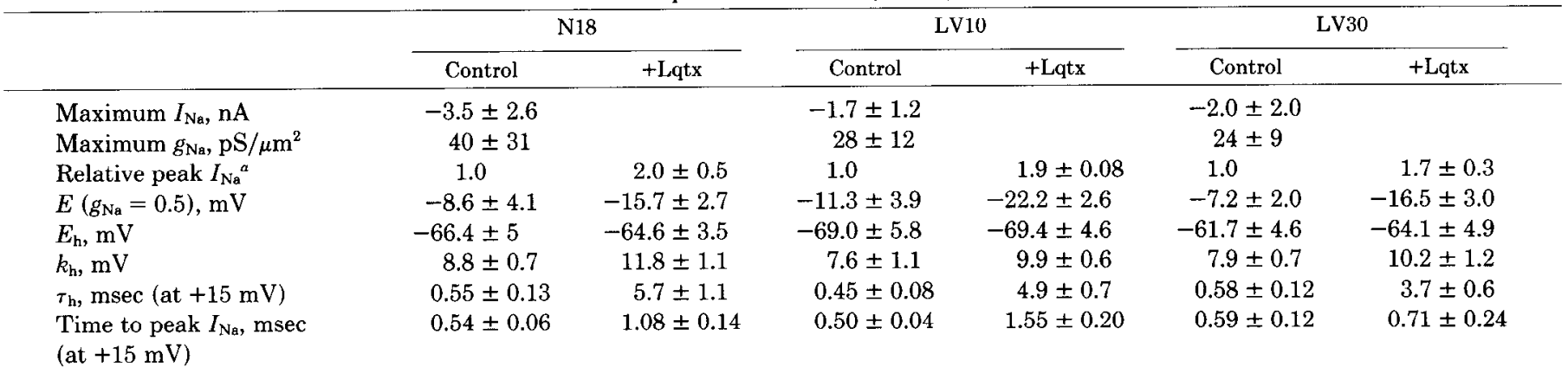

\footnotetext{
${ }^{a}$ Because individual cells vary greatly in maximum $I_{\mathrm{Na}}$, the effect of Lqtx on peak $I_{\mathrm{Na}}$ is reported as the ratio of $I_{\mathrm{Na}}$ at $0 \mathrm{mV}$ test pulse potential
} in individual cells before and after treatment with Lqtx. 


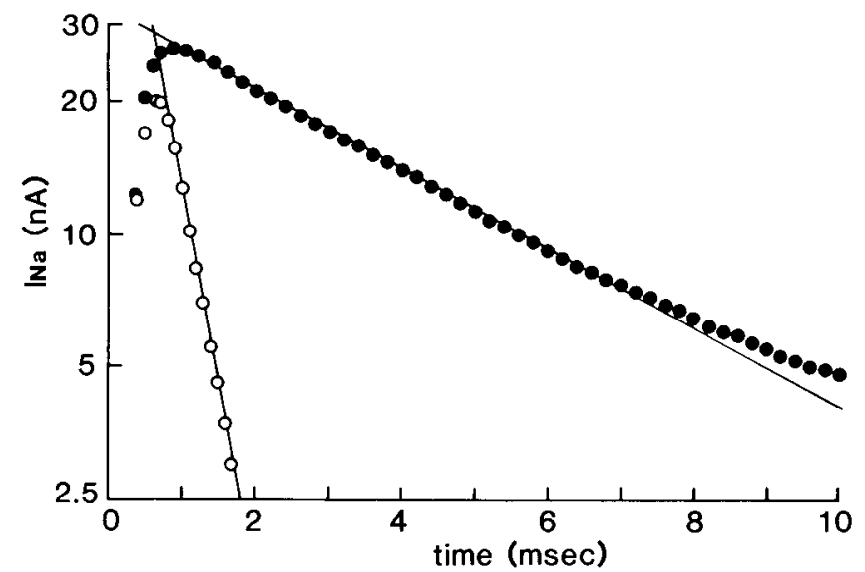

Figure 4. Time course of inactivation of sodium current in the presence and absence of Leiurus toxin. Sodium currents of N18 neuroblastoma cells were recorded during pulses to $+15 \mathrm{mV}$ as described under "Materials and Methods" before $(O)$ or $15 \mathrm{~min}$ after $(\Theta)$ the addition of $10 \mu \mathrm{M}$ Leiurus toxin. The exponential decay of the currents is illustrated on semilogarithmic coordinates. The limiting straight lines correspond to time constants of 0.48 and $4.9 \mathrm{msec}$ at $+15 \mathrm{mV}$.

and steady-state inactivation $\left(h_{\infty}\right)$. Peak currents in the presence and absence of Leiurus toxin were converted to conductance and normalized to the maximum conductance observed at $+30 \mathrm{mV}$. Typical curves for such normalized sodium conductance values as a function of test potential are illustrated in Figure 5 for N18 cells (open and solid squares). Leiurus toxin shifts the conductance activation curve by $9 \mathrm{mV}$ to more negative membrane potentials without changing its shape. Similar effects were observed for the scorpion toxin-resistant clones LV10 and LV30 (Table I). Apparently, slowing of inactivation with Leiurus toxin increases the maximum observed current and shifts the voltage dependence of activation to more negative values, effects not observed in studies with nonmammalian preparations. These effects occur in both normal and scorpion toxin-resistant neuroblastoma cells.

The effect of Leiurus scorpion toxin on the voltage dependence of sodium channel inactivation was determined using a two-pulse protocol in the presence and absence of $200 \mathrm{nM}$ toxin. Typical results for N18 cells are illustrated in Figure 5 (open and solid circles). As observed in a previous study with crude venom (Koppenhöfer and Schmidt, 1968a, b), Leiurus toxin does not significantly shift the midpoint of the inactivation curve but makes the dependence of inactivation on prepulse potential less steep and prevents complete inactivation at the most positive potentials examined. The mean maximum slope of the $h_{\infty}$ curve decreases from $e$-fold/ $8.8 \mathrm{mV}$ to $e$-fold/ $11.1 \mathrm{mV}$. Approximately $5 \%$ of the sodium current remained after 90 msec duration prepulses to $-15 \mathrm{mV}$ (Fig. 5). Similar effects were observed for the scorpion toxin-resistant cells lines (Table I).

Concentration dependence of Leiurus scorpion toxin action. Our results show that a saturating concentration of Leiurus toxin has similar effects on sodium channels in normal and scorpion toxin-resistant cell lines. However, since previous ${ }^{22} \mathrm{Na}^{+}$influx and $\left[{ }^{125} \mathrm{I}\right]$ scorpion toxin binding experiments with the mutant cell lines showed that apparent $K_{\mathrm{D}}$ values for Leiurus toxin are increased as compared to N18 (West and Catterall, 1979; Costa and Catterall, 1982), it is of interest to determine whether higher concentrations of Leiurus toxin are required to block inactivation in clones LV10 and LV30.

The results of Figure 4 show that in the absence of Leiurus toxin the sodium current at $+15 \mathrm{mV}$ has decayed to less than $2 \%$ of its maximum value $3 \mathrm{msec}$ after the peak, whereas in the presence of $200 \mathrm{nM}$ toxin approximately $60 \%$ of the peak

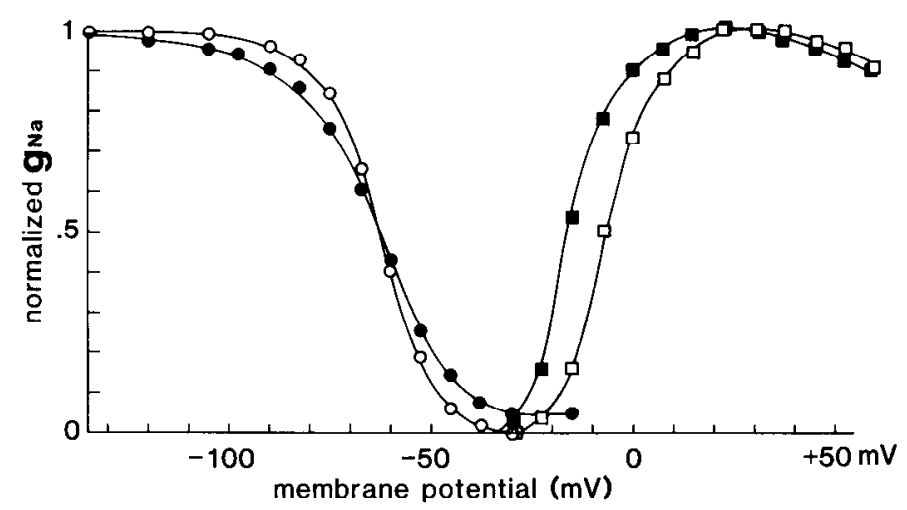

Figure 5. Effect of Leiurus toxin on the voltage dependence of activation and inactivation. Sodium currents of N18 neuroblastoma cells were measured during depolarizations to the indicated membrane potentials and conductance values were calculated and normalized to the maximum values observed in the absence $(\square)$ or presence $(\square)$ of $200 \mathrm{nM}$ Leiurus toxin. Steady-state inactivation of sodium currents was measured as described in the legend to Figure 2 and under "Materials and Methods" in the presence $(\bullet)$ or absence $(O)$ of $200 \mathrm{nM}$ Leiurus toxin.

current remains at this time. The fraction of current remaining $3 \mathrm{msec}$ after the peak is therefore proportional to the number of sodium channels with modified inactivation kinetics and can be used to determine the concentration dependence of toxin action. Our measurements were made by sampling many cells previously equilibrated with toxin at their normal resting potential (approximately $-40 \mathrm{mV}$ ). Sodium currents were recorded as soon as the electrode could be sealed on the cell and the $-75-\mathrm{mV}$ holding potential could be applied (always less than $3 \mathrm{~min}$ ). Figure 6 presents concentration-effect curves for Leiurus toxin action on clones N18, LV10, and LV30 measured in this way. In each case, the concentration-effect relationship fits a simple hyperbolic binding isotherm of the form:

$$
F_{G}=\bar{F}_{G} /\left(1+\frac{K_{\mathrm{D}}}{[L q t x]}\right)
$$

where $F_{G}$ is the fraction of sodium conductance remaining 3 msec after the peak, $\bar{F}_{G}$ is the maximum fraction at saturating scorpion toxin, and Lqtx is the concentration of Leiurus toxin. The best fit parameters describing the data of Figure 6 were N18, $\bar{F}_{G}=67 \%, K_{\mathrm{D}}=1.7 \mathrm{nM} ; \mathrm{LV} 30, \bar{F}_{G}=50 \%, K_{\mathrm{D}}=5.4 \mathrm{nM}$; LV10, $\bar{F}_{G}=58 \%, K_{\mathrm{D}}=24 \mathrm{nM}$. These results show that the apparent $K_{\mathrm{D}}$ for Leiurus toxin action in slowing inactivation is increased 3.2- and 14-fold in the resistant clones LV30 and LV10. Thus, the physiological data show that the mutant neuroblastoma cells have sodium channels with normal functional properties and confirm the previous conclusion that their channels have reduced affinity for Leiurus toxin.

Voltage dependence of Leiurus toxin action. The affinity of ${ }^{125}$ I-labeled Leiurus toxin for its receptor site on the sodium channel decreases sharply with membrane depolarization by $\mathrm{K}^{+}$(Catterall, 1977, 1979). Similarly, slowing of channel inactivation by a Buthus scorpion toxin is reduced by prolonged depolarization of the frog node of Ranvier under voltage clamp (Mozhayeva et al., 1980). It is of interest, therefore, to examine the voltage dependence of scorpion toxin binding and action in normal and scorpion toxin-resistant neuroblastoma cells over a range of membrane potentials. As in the experiments of Mozhayeva et al. (1980), we changed the holding potential for several minutes to allow toxin binding to re-equilibrate and then evoked a sodium current with a standard prepulse/test pulse combination to assay what fraction of sodium channels had modified kinetics. Figure 7 illustrates the effect of changing the holding potential from $+30 \mathrm{mV}$ to $-105 \mathrm{mV}$ on the block of channel inactivation by scorpion toxin. N18 cells had been 


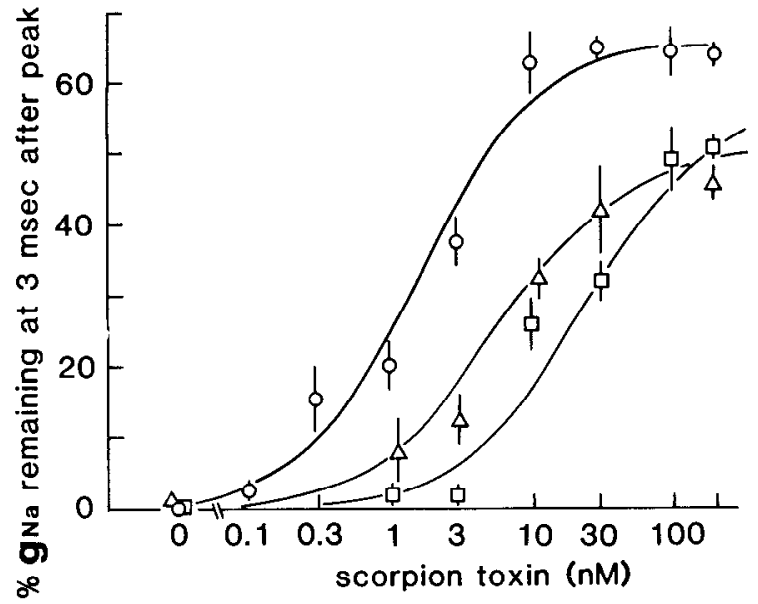

Figure 6. Concentration-effect relationships for prolongation of sodium currents by Leiurus toxin. Cells were incubated for $30 \mathrm{~min}$ at $37^{\circ} \mathrm{C}$ with the indicated concentrations of Leiurus toxin. Sodium currents were then measured at $20^{\circ} \mathrm{C}$ during depolarization to $+15 \mathrm{mV}$, and the percentage of the peak current remaining $3 \mathrm{msec}$ after the peak was estimated. Mean values ( $\pm \mathrm{SE}$ ) are presented for 4 to 11 cells for clones N18 $(O)$, LV10 $(\square)$, and LV30 $(\triangle)$. Smooth curves are drawn assuming one-to-one, noncooperative binding of Leiurus toxin to sodium channels.

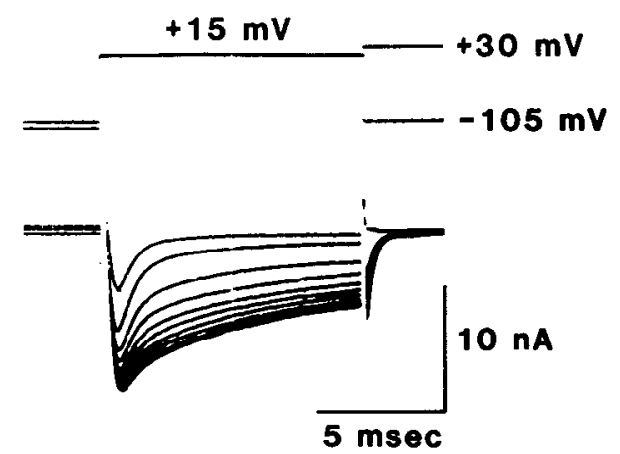

Figure 7. Time course of voltage-dependent Leiurus toxin action. An N18 cell was incubated with $5 \mathrm{nM}$ Leiurus toxin for $30 \mathrm{~min}$ at $37^{\circ} \mathrm{C}$ and then depolarized in several steps to $+30 \mathrm{mV}$. The first sodium current (top trace) was elicited by a hyperpolarization to $-120 \mathrm{mV}$ for $390 \mathrm{msec}$ followed by a test pulse to $+15 \mathrm{mV}$. The holding potential was then changed to $-105 \mathrm{mV}$ and sodium currents during a 10 -msec test pulse to $+15 \mathrm{mV}$. were recorded every $10 \mathrm{sec}$.

preincubated with $5 \mathrm{nM}$ Leiurus toxin at $37^{\circ} \mathrm{C}$ for $30 \mathrm{~min}$. After a cell patch was formed, the cell was depolarized in several steps to $+30 \mathrm{mV}$ and held there for $7 \mathrm{~min}$. The cell was then repolarized to $-120 \mathrm{mV}$ for $390 \mathrm{msec}$, and a sodium current was recorded during a $10-\mathrm{msec}$ test pulse to $+15 \mathrm{mV}$. The holding potential was then stepped to $-105 \mathrm{mV}$ and test pulses to $+15 \mathrm{mV}$ of $10 \mathrm{msec}$ duration were applied every $10 \mathrm{sec}$. Initially, a small sodium current is evoked which decays rapidly (Fig. 7). In each successive pulse the sodium current increases in amplitude and duration until a new steady state is reached after $100 \mathrm{sec}$. These changes reflect a combination of two voltage-dependent processes: the binding and action of scorpion toxin and the return of sodium channels from "slow inactivated" states induced by long depolarization. The time constant for redevelopment of the toxin effect is less than $30 \mathrm{sec}$ in this experiment, corresponding to a forward rate constant of binding larger than $7 \times 10^{6} \mathrm{M}^{-1} \mathrm{sec}^{-1}$. In control experiments without toxin, recovery of sodium channels from "slow inactivated" states was complete in less than $10 \mathrm{sec}$.

In order to measure the voltage dependence of scorpion toxin binding, experiments like the one illustrated in Figure 7 were carried out with holding potential levels between +60 and -105 $\mathrm{mV}$, and the fraction of sodium channels with toxin-modified inactivation kinetics was estimated by measuring the fraction of the sodium current remaining $3 \mathrm{msec}$ after the peak. Apparent $K_{\mathrm{D}}$ values were calculated at each membrane potential according to the relationship

$$
K_{\mathrm{D}}=[L q t x]\left(\frac{\bar{F}_{G}}{F_{i}}-1\right)
$$

where the symbols have the same meaning as above. These apparent $K_{\mathrm{D}}$ values are plotted against the holding potential in Figure 8 for N18, LV30, and LV10. In each case, $K_{\mathrm{D}}$ values change over a similar range of membrane potentials, although their absolute values differ substantially. The three lines in Figure 8 correspond to $K_{\mathrm{D}} \mathrm{s}$ at $-40 \mathrm{mV}$ of $1.6,39$, and $51 \mathrm{nM}$, respectively, and slopes of $e$-fold increases of $K_{\mathrm{D}}$ for 19,19 , and $16 \mathrm{mV}$ of depolarization. Thus, scorpion toxin binding remains steeply voltage dependent in toxin-resistant neuroblastoma cells. The $K_{\mathrm{D}}$ values for the mutant cell lines were significantly higher in this series of experiments than in the previous series (Fig. 6) in which a range of toxin concentrations was examined at the resting membrane potential of the cells. The reason for this quantitative difference was not explored further.

\section{Discussion}

Modification of sodium currents by scorpion toxin in a mammalian neuronal cell. Previous voltage clamp studies with scorpion toxin used nonmammalian nerve and muscle preparations. The principal effects of the toxin in these studies are to slow inactivation of the sodium channel, to make the $h_{\infty}$ curve less steep, and, in many cases, to make inactivation incomplete. These actions are also observed in our studies of mouse neuroblastoma cells. In addition, we see two new aspects of the action of Leiurus toxin that may be characteristic of mammalian sodium channels. First, Leiurus toxin increased peak sodium currents approximately 2 -fold whereas the amplitude of the sodium current was either unchanged or reduced in previous studies of nonmammalian cells (Koppenhöfer and Schmidt, 1968a; Narahashi et al., 1972; Romey et al., 1975; Catterall, 1979; Mozhayeva et al., 1980). Second, Leiurus toxin caused a

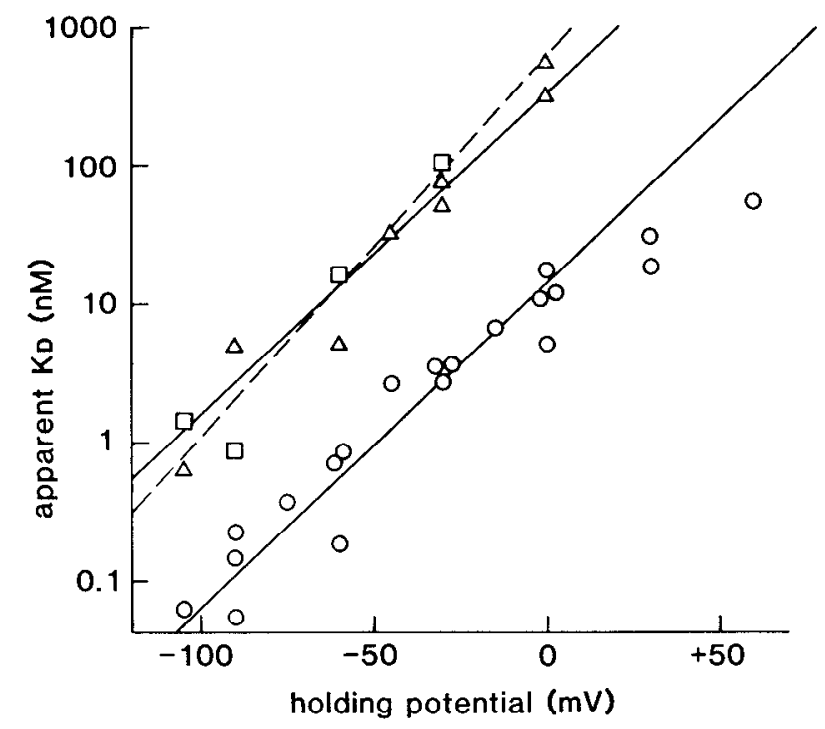

Figure 8. Voltage dependence of Leiurus toxin action in N18, LV10, and LV30. Sodium currents were measured as in Figure 7 at steady state for holding potentials ranging from $+60 \mathrm{mV}$ to $-105 \mathrm{mV}$, and $F_{G}$ was estimated. $K_{\mathrm{D}}$ values were then calculated from the relationship given in the text for N18 (O), LV10 $(\square--\square)$, and LV30 ( $\triangle$ ) cells. The regression lines are described in the text. 
larger shift of the $g_{\mathrm{Na}}$ versus voltage curve to more negative membrane potentials than has been previously observed. These new effects of scorpion toxin may result from quantitative differences in the gating properties of mammalian sodium channels that have been noted in previous studies. Voltage clamp studies of rabbit node of Ranvier (Chiu et al., 1979), rat skeletal muscle cells (Patlak and Horn, 1982), and mouse neuroblastoma cells (Aldrich et al., 1983) indicate that inactivation of mammalian sodium channels is more rapid than previously observed in nonmammalian preparations. When inactivation is fast, a small fraction of the channels will be open at the peak of the sodium current. Slowing of inactivation by scorpion toxin could then increase the peak sodium current by prolonging the open time of individual channels and thereby permitting a larger fraction to be open simultaneously. Elimination of inactivation of sodium channels in rat myotubes with pronase or $N$-bromoacetamide also increases the probability that sodium channels are open during a test pulse (Patlak and Horn, 1982).

This hypothesis can be illustrated qualitatively using the equation of Hodgkin and Huxley (1952) to fit the time course of a sodium current: $I_{\mathrm{Na}}=I_{0}\left(1-\mathrm{e}^{-1 / \tau_{m}}\right)^{3}\left(e^{-1 / \tau h}\right)$. Values of $\tau_{m}$ $=0.17 \mathrm{msec}$ and $\tau_{h}=0.55 \mathrm{msec}$ fit our data at $+15 \mathrm{mV}$ in the absence of scorpion toxin. If $\tau_{h}$ is increased to $5.7 \mathrm{msec}$ in the presence of scorpion toxin, this equation predicts a 2.3 -fold increase in peak current and a 1.8-fold increase in the time to reach peak current, much like what we observe (Table I).

A similar explanation could account for the shift of the peak $g_{\mathrm{Na}}$ versus voltage curve to more negative potentials. Others have suggested that the elementary rate constant underlying inactivation in several kinds of cells is nearly independent of voltage (Bezanilla and Armstrong, 1977; Nonner, 1980; Aldrich et al., 1983). In that case, slowing of this elementary rate constant would have a larger effect on peak currents at small depolarizations (where activation is slow) than at large depolarizations (where activation is fast), an effect equivalent to a shift combined with an increase of peak $P_{\text {Na. }}$. The possibility must also be considered that the shift is an artifact of the increased $I_{\mathrm{Na}}$ flowing in residual uncompensated series resistance between the bath and cell electrodes. We tested for this artifact by comparing the voltage dependence of $I_{\mathrm{Na}}$ in the standard Ringer solution containing $150 \mathrm{mM} \mathrm{NaCl}$ with that in a solution with only $30 \mathrm{mM} \mathrm{NaCl}$ (and $120 \mathrm{mM}$ tetraethylammonium chloride) where peak $I_{\mathrm{Na}}$ was about 5 times smaller. For normal N18 cells, diluting the $\left[\mathrm{Na}^{+}\right]$shifted the midpoint of the activation curve by only $+2.1 \pm 1.4 \mathrm{mV}$. The same manipulation on cells already treated with scorpion toxin shifted the midpoint by $+2.9 \mathrm{mV}$. Hence we conclude that most of the -7 to $-11 \mathrm{mV}$ shift caused by scorpion toxin treatment (Table I) is a bona fide shift of activation, and at most a couple of millivolts may be attributed to a series resistance artifact.

Modification of the sodium currents by Leiurus toxin is voltage dependent. The apparent $K_{\mathrm{D}}$ for modification increases $e$-fold for each 16 to $19 \mathrm{mV}$ of depolarization in N18, LV10, or LV30 cells. The voltage dependence of modification of the currents observed here ranges between the voltage dependence of Leiurus toxin binding to N18 cell sodium channels ( $e$-fold increase $/ 13.5 \mathrm{mV}$; Catterall, 1977), and the voltage dependence of Buthus eupeus toxin modification of sodium currents on frog myelinated fibers and Leiurus toxin binding on frog muscles (e-fold increase per 19.5 and $22.3 \mathrm{mV}$ depolarization, respectively; Catterall, 1979; Mozhayeva et al., 1980). Voltage-dependent Leiurus toxin binding is characteristic of both mammalian and nonmammalian sodium channels.

Properties of sodium channels in scorpion toxin-resistant neuroblastoma cells. A major objective of this study was to examine the functional properties of sodium channels in variant neuroblastoma cells that are resistant to the cytotoxic effect of scorpion toxin and have reduced toxin affinity for scorpion toxin in biochemical experiments. We find that the functional properties of the channels are unchanged. Sodium conductancevoltage relationships, $h_{\infty}$-voltage relationships, and the rise and decay times of the sodium currents were essentially similar among N18, LV10, and LV30 cells. The peak sodium conductance may be reduced 35 to $40 \%$ in the variant cells, consistent with a reduction in sodium channel density in the surface membrane of these cells. We conclude that the mutations leading to scorpin toxin resistance have a specific effect on the scorpion toxin receptor site without causing other major defects in channel function.

Saturating concentrations of Leiurus toxin cause a similar modification of the sodium currents in both normal and mutant cells. The decay of the sodium current is prolonged 6- to 10 fold, the peak sodium conductance is increased 1.9- to 2.0-fold, the steepness of the $h_{\infty}$ curve is reduced 1.3-fold, and the $g_{\mathrm{Na}}$ versus voltage curve is shifted -8 to $-11 \mathrm{mV}$ in each case. The voltage dependence of Leiurus toxin action is similar in each case. These results indicate that the effects of Leiurus toxin that occur subsequent to toxin binding are not altered in the mutant cells.

The only observed alteration in sodium channel properties is a lowered affinity for Leiurus toxin. The mutant cells I,V30 and LV10 have apparent $K_{\mathrm{D}}$ values that are 3 - to 10 -fold and 14 -fold greater than for N18 cells, respectively. The $K_{\mathrm{D}}$ values measured are in reasonable agreement with previous biochemical studies. Thus, for N18 cells, $K_{\mathrm{D}}$ values of $1.7 \mathrm{nM}$ were ohserved in these experiments compared to $0.7 \mathrm{nM}$ previously (Catterall, 1977; Costa and Catterall, 1982); for LV30 cells values of $5.4 \mathrm{nM}$ and $39 \mathrm{nM}$ were observed compared to 5 or 19 nM (Costa and Catterall, 1982), and for LV10 cells values of 24 $\mathrm{nM}$ and $51 \mathrm{nM}$ were observed compared to $24 \mathrm{nM}$ (West and Catterall, 1979). Since these modifications in Leiurus toxinbinding affinity are specific, determination of the changes in channel structure that cause them will identify components essential for toxin binding. These mutant cell lines will be useful reagents in studies of the relationship between molecular structure and physiological function of the voltage-sensitive sodium channel.

\section{References}

Aldrich, R. W., D. P. Corey, and C. F. Stevens (1983) A reinterpretation of mammalian sodium channel gating based on single channel recording. Nature (Lond.) 306: 436-441.

Barchi, R. L. (1983) Protein components of the purified sodium channel from rat skeletal muscle sarcolemma. J. Neurochem. 40: 1377-1385.

Bezanilla, F., and C. M. Armstrong (1977) Inactivation of the sodium channel. I. Sodium current experiments. J. Gen. Physiol. 70: 549566.

Catterall, W. A. (1975) Activation of the action potential sodium ionophore by veratridine and batrachotoxin. J. Biol. Chem. 250: $4053-4059$.

Catterall, W. A. (1976) Purification of a toxic protein from scorpion venom which activates the action potential $\mathrm{Na}^{+}$ionophore. J. Biol. Chem. 251: 5528-5536.

Catterall, W. A. (1977) Membrane potential-dependent binding of scorpion toxin to the action potential $\mathrm{Na}^{+}$ionophore. Studies with a Loxin derivative prepared by lactoperoxidase-catalyzed iodination. $\mathrm{J}$. Biol. Chem. 252: 8660-8668.

Catterall, W. A. (1979) Binding of scorpion toxin to receptor sites associated with sodium channels in frog muscle. J. Gen. Physiol. 74: $375-391$.

Catterall, W. A. (1984) The molecular basis of neuronal excitability. Science 223: 653-661.

Chiu, S. Y., J. M. Ritchie, R. B. Rogart and D. Stagg (1979) A quantitative description of membrane currents in rabbit myelinated nerve. J. Physiol. (Lond.) 292: 149-166.

Costa, M. R., and W. A. Catterall (1982) Characterization of variant neuroblastoma clones with missing or altered sodium channels. Mol. Pharmacol. 22: 196-203. 
Hamill, O. P., A. Marty, E. Neher, B. Sakmann, and F. J. Sigworth (1981) Improved patch-clamp techniques for high-resolution current recording from cells and cell-free membrane patches. Pflügers Arch. 391: 85-100.

Hodgkin, A. L., and A. F. Huxley (1952) A quantitative description of membrane current and its application to conduction and excitation in nerve. J. Physiol. (Lond.) 117: 500-544.

Huang, L. -Y., N. Moran, and G. Ehrenstein (1982) Batrachotoxin modifies the gating kinetics of sodium channels in internally perfused neuroblastoma cells. Proc. Natl. Acad. Sci. U. S. A. 79: 2082-2085.

Koppenhöfer, E., and H. Schmidt (1968a) Die Wirkung von Skorpiongift auf die Ionenströme des Ranvierschen Schnürrings. I. Die Permeabilitäten $\mathrm{P}_{\mathrm{Na}}$ und $\mathrm{P}_{\mathrm{K}}$. Pflügers Arch. 303: 133-149.

Koppenhöfer,E., and H. Schmidt (1968b) Die Wirkung von Skorpiongift auf die Ionenströme des Ranvierschen Schnürrings. II. Unvollständige Natrium Inaktivierung. Pflügers Arch. 303: 150-161.

Kostyuk, P. G., O. A. Krishtal, V. I. Pidoplichko, and N. S. Veselovsky (1978) Ionic currents in the neuroblastoma cell membrane. Neuroscience 3: $327-332$.

Moolenaar, W. H., and I. Spector (1978) Ionic currents in cultured mouse neuroblastoma cells under voltage-clamp conditions. J. Physiol. (Lond.) 278: 265-286.

Mozhayeva, G. N., A. P. Naumov, E. D. Nosyreva, and E. V. Grishin (1980) Potential-dependent interaction of toxin from venom of the scorpion Buthus eupeus with sodium channels in myelinated fibre.
Biochim. Biophys. Acta 597: 587-602.

Narahashi, T., B. I. Shapiro, T. Deguchi, M. Scuka, and C. M. Wang (1972) Am. J. Physiol. 222: 850-857.

Nonner, W. (1980) Relations between the inactivation of sodium channels and the immobilization of gating charge in frog myelinated nerve. J. Physiol. (Lond.) 299: 573-603.

Okamoto, II., K. Takahashi, and N. Yamashita (1977) One-to-one binding of a purified scorpion toxin to $\mathrm{Na}$ channels. Nature 266: $465-468$.

Patlak, J., and R. Horn (1982) Effect of $N$-bromoacetamide on single sodium channel currents in excised membrane patches. J. Gen. Physiol. 79: 333-351.

Quandt, F. N., and T. Narahashi (1982) Modification of single sodium channels by batrachotoxin. Proc. Natl. Acad. Sci. U. S. A. 79: 67326736.

Romey, G., R. Chicheportiche, and M. Lazdunski (1975) Scorpion neurotoxin-A presynaptic toxin which affects both $\mathrm{Na}^{+}$and $\mathrm{K}^{+}$ channels in axons. Biochem. Biophys. Res. Commun. 64: 115-121.

Wang, G. K., and G. R. Strichartz (1983) Purification and physiological characterization of neurotoxins from venoms of the scorpions Centruroides sculpturatus and Leiurus quinquestriatus. Mol. Pharmacol. 23: 519-533.

West, G. W., and W. A. Catterall (1979) Selection of variant neuroblastoma clones with missing or altered sodium channels. Proc. Natl. Acad. Sci. U. S. A. 76: 4136-4140. 